\title{
Fine Anthracite Coal Washing Using Spirals
}

\section{Office of Science \& Technology \\ Research Report}

R.P. Killmeyer ${ }^{1}$, P.H. Zandhuis ${ }^{2}$, M.V. Ciocco ${ }^{2}$, W. Weldon ${ }^{3}$,

T. West ${ }^{4}$, and D. Petrunak ${ }^{4}$

${ }^{1}$ U.S. Department of Energy/NETL

${ }^{2}$ Parsons Project Services, Inc.

${ }^{3}$ MD Mineral Technologies, Inc.

${ }^{4}$ Sedgman, Inc.

U.S. Department of Energy

National Energy Technology Laboratory

Office of Science \& Technology

P.O. Box 10940, 626 Cochrans Mill Road

Pittsburgh, PA 15236-0940

May 2001 


\section{Disclaimer}

This report was prepared as an account of work sponsored by an agency of the United States Government. Neither the United States Government nor any agency thereof, nor any of their employees, makes any warranty, express or implied, or assumes any legal liability or responsibility for the accuracy, completeness, or usefulness of any information, apparatus, product, or process disclosed, or represents that its use would not infringe privately owned rights. Reference therein to any specific commercial product, process, or service by trade name, trademark, manufacturer, or otherwise does not necessarily constitute or imply its endorsement, recommendation, or favoring by the United States Government or any agency thereof. The views and opinions of authors expressed therein do not necessarily state or reflect those of the United States Government or any agency thereof. 


\section{Background}

Historically, fine anthracite coal has been washed on Deister tables. The size processed includes \#4 buck at 3/32 in. $x$ 3/64 in. (8 by 16 US mesh), and \#5 buck at 3/64 in. $x 100$ mesh (16 by 100 US mesh.) Today's marketplace is presenting the anthracite industry with opportunities for fixed carbon applications (filter media, metallurgical carbon, etc.) The related quality specifications are more stringent, requiring consistently lower ash $( \pm 8$ percent $)$ and minimum misplaced material in product size fraction. For this reason, Sedgman, Inc. conducted a feasibility study for Kocher Coal Company in eastern Pennsylvania on the possibility of only using more efficient and easier-to-operate spirals to treat this wide size range.

However, a spiral normally only processes the 16 x 100 mesh size fraction, so there was some question about how well it could accommodate the coarser $8 \times 16$ mesh fraction. As a result, the U.S. Department of Energy, National Energy Technology Laboratory (NETL) was asked to perform a short pilot-scale test program utilizing fine anthracite in a spiral to detail the separation performance that might be expected from spirals supplied by MD Mineral Technologies. Test variables included flow rate, solids concentration, solids throughput, and spiral cutter position. Partition curves were developed from washability data for selected tests to define performance for both the $8 \times 16$ mesh and the $16 \times 100$ mesh size fractions.

\section{Spiral Circuit Description}

MD Mineral Technologies supplied a model LD7 spiral, which is designed to handle about 30 to $40 \mathrm{gal} / \mathrm{min}$ of feed slurry at about 30 percent solids, resulting in a throughput of $3 \mathrm{tons} / \mathrm{h}$. A closed-loop spiral circuit was fabricated in NETL's Solids Processing Research Facility (SPRF), as shown in Figure 1.

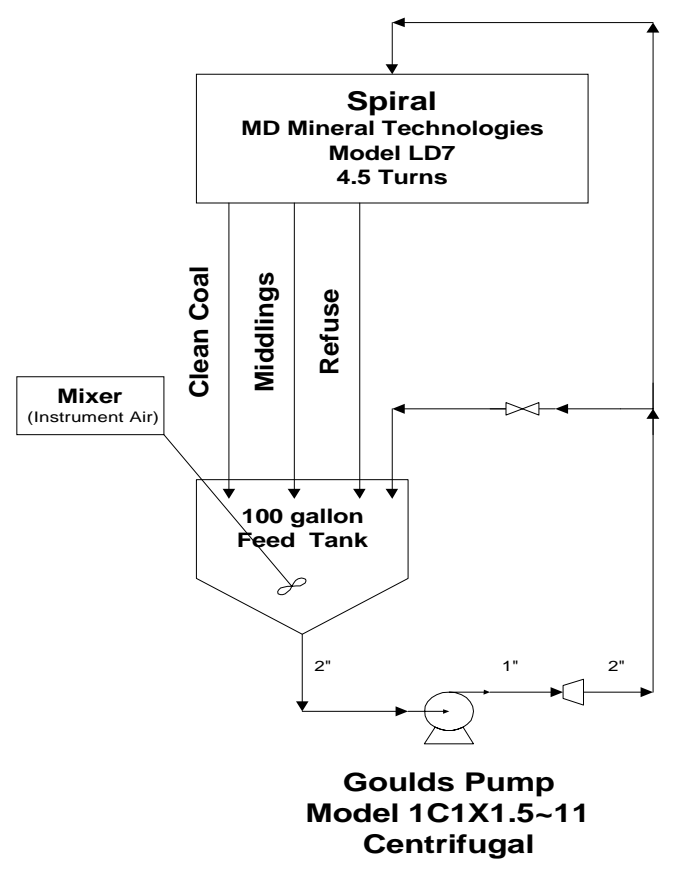

Figure 1. Schematic of Spiral Unit 
The testing was conducted on four separate dates using two lots of anthracite coal that originated from the Kocher Coal Company located just east of Carlisle, Pennsylvania.

\section{Coal Sample}

Two lots of coal delivered to NETL consisted of about $800 \mathrm{lb}$ and $500 \mathrm{lb}$ from the preparation plant. Both lots contained a considerable amount of +8 mesh material (about 35 percent and 53 percent, respectively). The +8 mesh material was dry-screened from the sample and reground in a hammermill for further use. The sample was then wet-screened to remove the bulk of the -100 mesh material, leaving primarily the $8 \times 100$ mesh fraction as the feed to the spiral. The resulting feed coal had the approximate size consist shown in Table 1.

\section{Table 1. Feed Coal Size Consist}

\begin{tabular}{|c|c|}
\hline Fraction (US Series) & Wt.\% Range \\
\hline+8 mesh & 1 to 3 \\
\hline $8 \times 16$ mesh & 17 to 27 \\
\hline $16 \times 100$ mesh & 46 to 55 \\
\hline-100 mesh & 21 to 27 \\
\hline
\end{tabular}

The washability analyses of the two samples are plotted in Figure 2. The points represent the cumulative float values at specific gravities of 1.6, 1.8, 2.0, and 2.4. Figure 2 shows that both samples had similar cleaning potentials, which means they should produce similar clean coal ash contents at equivalent weight yields. The washability curve also shows that the coal has a fair amount of near-gravity material ( 10 percent) at a specific gravity of 1.80 , which is the normal cutpoint region for spirals. This indicates that the coal would be moderately difficult to separate in a spiral.

Anthracite Feed Washability (8X100 mesh)

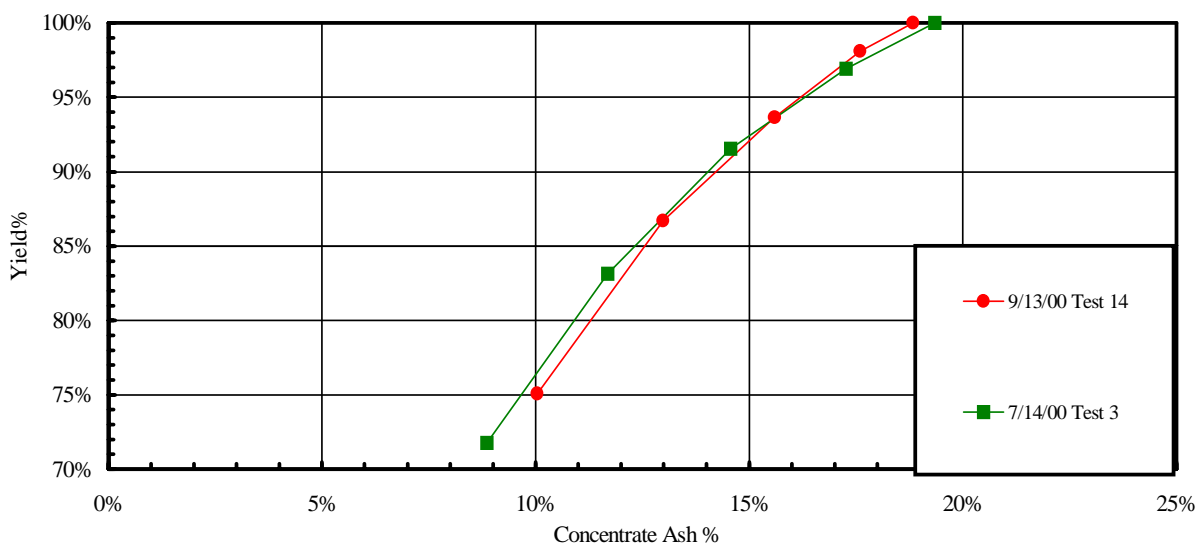

Figure 2. Washability Analyses of Two Samples 


\section{Test Procedure}

The coal and water fractions were weighed and added to the feed tank to prepare the slurry. A test consisted of the following protocol: verify flow rate and percent solids of the feed, set the two spiral cutters to the desired positions (see Figure 3), allow a minute for the flows to become established, obtain timed samples from all three spiral streams, and sample the feed stream from the feed tank recycle line. In Figure 3, the slurry would be flowing from the top towards the bottom, with "outside" referring to the outer wall of the spiral where the clean coal concentrates. "Inside" refers to the inner wall of the spiral where the refuse tends to concentrate.
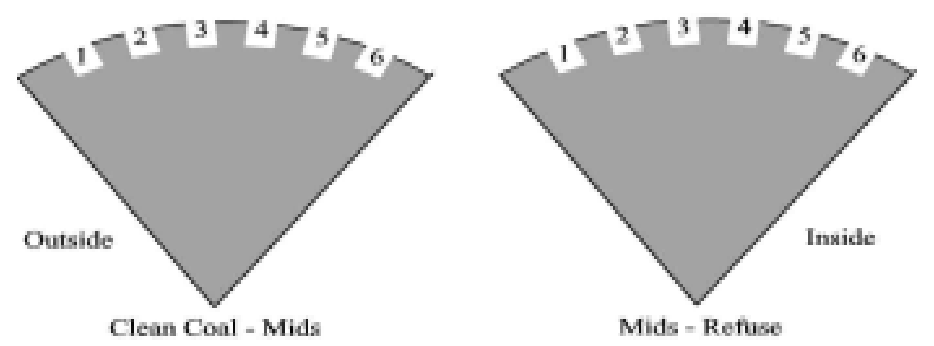

\section{Figure 3. Spiral Cutter Positions}

The testing for each of the four days was organized as follows:

7/13/00: $\quad$ Five tests were conducted at generally high flow rates (60 gal $/ \mathrm{min})$ and high solids concentrations ( 30 to $35 \%$ ), resulting in high solids feed rates (4 to 5 tons/h.)

8/14/00: $\quad$ Two tests were conducted at relatively medium flow rates (40 gal $/ \mathrm{min}$ ) and low solids concentrations (19\%), resulting in low feed rates (2 tons/h.)

8/18/00: $\quad$ Four tests were run at similarly medium flow rates (40 gal $/ \mathrm{min}$ ) but high solids concentrations $(30 \%)$, resulting in fairly high feed rates (4 tons/h.)

9/13/00: $\quad$ Four tests were run at middle conditions of flow rate (36 gal $/ \mathrm{min})$ and solids concentration $(25 \%)$, resulting in a medium feed rate $(3$ tons $/ \mathrm{h}$.

Timed samples of the clean coal, middlings, and refuse were collected in tared buckets and then weighed. Each of the samples was sized at 8, 16, and 100 mesh (US Series). All of the size fractions were analyzed for ash. In addition to the size and ash analyses, a washability analysis was conducted on the products from Tests 3,14 , and 15. 


\section{Results}

Table 2 summarizes the 17 spiral tests in terms of the overall ( 8 mesh by 0 ) clean coal, middlings, and refuse product quality. Significant changes in the operating conditions of flow rate ( $\mathrm{gal} / \mathrm{min})$ and feed solids concentrations (\%) are indicated in bold italics; their levels determined the resulting feed dry tons/hr (DTPH). Figure 2 has been added as a guide in visualizing the settings for the two splitters for each test.

The results show that this anthracite coal is difficult to clean in a spiral, as the washability analysis indicated. Starting with a raw coal ash of about 22 percent for the 8 mesh by 0 , the clean coal ash contents were relatively high at about 18 percent at a yield of about 77 percent when averaging the results from all 17 tests, while the refuse ash contents were slightly low at about 55 percent. This figure did not even include the middlings, which are generally combined with the refuse. The middlings ash content was not much higher than the feed coal at about 31 percent.

A lot of the ash in the clean coal can be attributed to the -100 mesh material, which would not normally be part of the product. It accounted for about 28 percent of the clean coal by weight and averaged about 29 percent ash, experiencing virtually no cleaning. Considering just the normal clean coal product size of $8 \times 100$ mesh, the spiral reduced the $8 \times 100$ feed coal from 19 percent ash down to about 13 percent ash.

Changes in the main operating variables of feed rate and feed solids concentration did not produce significant changes in the quality or yield of the various product streams. Changes in the splitter settings had a bigger impact on the product characteristics.

As touched on earlier, the main reasons for the small ash reduction are fairly straightforward:

- The anthracite washability shows that it is not conducive to a "black and white" separation, and

- The amount of near-gravity material in the cut-point region of the spiral produces a high degree of particle crowding, resulting in a significant amount of misplaced material.

Even though the separation task was formidable because of the coal characteristics, the spiral still performed well. Table 3 highlights the performance of the spiral obtained from the washability analyses conducted on the products from Tests 3,14 , and 15 . Partition curves were constructed by combining the analyses from the middlings and the refuse into one tailings product that was, in effect, separated from the clean coal product. Figures 3 through 5 show the partition curves from which the performance parameters were derived. 
Table 2. Spiral Test Results for 8 mesh x 0 Products

\begin{tabular}{|c|c|c|c|c|c|c|c|c|c|c|c|c|c|c|c|c|c|}
\hline Test & 1 & 2 & 3 & 4 & 5 & 6 & 7 & 8 & 9 & 10 & 11 & 12 & 13 & 14 & 15 & 16 & 17 \\
\hline Date & $7 / 14$ & $7 / 14$ & $7 / 14$ & $7 / 14$ & $7 / 14$ & $8 / 14$ & $8 / 14$ & $8 / 18$ & $8 / 18$ & $8 / 18$ & $8 / 18$ & $9 / 13$ & $9 / 13$ & $9 / 13$ & $9 / 13$ & $9 / 13$ & $9 / 13$ \\
\hline CC/Mid & 6 & 4 & 2 & 4 & 2 & 5 & 1 & 5 & 4 & 4 & 3.5 & 5 & 4 & 3.5 & 3.5 & 4 & 4.5 \\
\hline Mid/Ref & 6 & 4 & 2 & 4 & 3 & 3 & 3 & 3 & 3 & 2 & 2 & 4 & 4 & 4 & 4 & 4 & 4 \\
\hline Feed gal/min & 3.53 & 56.94 & 59.10 & 52.77 & 50.66 & 41.36 & 39.74 & 39.06 & 39.80 & 39.38 & 38.07 & 37.81 & 38.30 & 36.58 & 36.21 & 37.94 & 34.68 \\
\hline $\mathrm{CC}$ gal/min & 60.28 & 51.96 & 52.79 & 49.29 & 44.17 & 39.02 & 31.51 & 34.42 & 33.99 & 33.95 & 32.10 & 33.64 & 32.66 & 31.01 & 30.58 & 37.71 & 30.12 \\
\hline Mid gal/min & 2.62 & 3.66 & 4.56 & 2.17 & 4.11 & 1.31 & 6.41 & 2.12 & 3.27 & 2.48 & 3.04 & 2.31 & 3.18 & 3.89 & 3.76 & 3.37 & 2.69 \\
\hline Ref gal/min & 0.63 & 1.32 & 1.75 & 1.30 & 2.38 & 1.03 & 1.82 & 2.52 & 2.54 & 2.95 & 2.93 & 1.85 & 2.46 & 1.68 & 1.87 & 1.86 & 1.86 \\
\hline Feed DTPH & 5.10 & 3.80 & 4.30 & 4.97 & 4.84 & 1.85 & 2.06 & 4.01 & 3.92 & 3.91 & 3.71 & 2.79 & 2.96 & 2.53 & 3.19 & 2.73 & 2.98 \\
\hline Mid I & 0.49 & 0.58 & 0.57 & 0.36 & 0.57 & 0.19 & 1.14 & 0.31 & 0.47 & 0.34 & 0.44 & 0.29 & 0.41 & 0.37 & 0.56 & 0.38 & 0.28 \\
\hline Ref DTPH & 0.12 & 0.26 & 0.25 & 0.25 & 0.40 & 0.27 & 0.19 & 0.41 & 0.36 & 0.49 & 0.46 & 0.34 & 0.34 & 0.18 & 0.26 & 0.25 & 0.16 \\
\hline Feed \% Soli & 1.28 & 28.23 & 31.08 & 35.12 & 35.12 & 19.07 & 19.07 & 30.24 & 33.33 & 30.86 & 30.31 & 23.06 & 21.76 & 22.25 & 25.28 & 25.26 & 25.38 \\
\hline CC \% Solids & .59 & 25.36 & 23.33 & 33.33 & 29.97 & 15.24 & 8.62 & 31.38 & 30.85 & 30.78 & 29.81 & 24.17 & 21.32 & 18.92 & 25.25 & 20.65 & 25.40 \\
\hline Mid \% Solids & 52.51 & 46.15 & 41.82 & 49.99 & 46.04 & 46.24 & 49.65 & 48.24 & 47.13 & 45.04 & 47.05 & 41.37 & 44.10 & 38.29 & 49.88 & 39.81 & 39.09 \\
\hline Ref \% Solids & 56.93 & 54.14 & 47.20 & 55.21 & 43.31 & 67.02 & 50.98 & 54.99 & 47.36 & 54.29 & 51.86 & 53.93 & 58.07 & 59.22 & 50.68 & 50.00 & 45.68 \\
\hline Feed Ash & 22.53 & 21.89 & 20.40 & 21.46 & 21.07 & 20.91 & 21.61 & 24.32 & 23.32 & 23.33 & 23.02 & 23.56 & 24.42 & 22.10 & 22.73 & 22.44 & 21.63 \\
\hline CC Ash & 18.39 & 15.83 & 17.51 & 17.60 & 16.64 & 14.32 & 20.71 & 19.36 & 18.44 & 18.03 & 18.27 & 17.09 & 17.71 & 17.80 & 17.87 & 17.43 & 18.33 \\
\hline Ref Ash & 67.84 & 58.95 & 48.73 & 58.29 & 53.06 & 49.12 & 40.36 & 55.72 & 52.41 & 51.46 & 47.81 & 58.82 & 61.98 & 53.42 & 54.58 & 58.46 & 60.50 \\
\hline CC Yield & 87.97 & 77.81 & 80.96 & 87.74 & 79.95 & 75.00 & 35.10 & 82.02 & 78.76 & 78.74 & 75.63 & 77.42 & 74.64 & 78.06 & 74.34 & 77.12 & 85.49 \\
\hline Mid Yield & 9.60 & 15.38 & 13.22 & 7.28 & 11.80 & 10.48 & 55.51 & 7.76 & 12.02 & 8.69 & 11.86 & 10.46 & 13.88 & 14.76 & 17.48 & 13.91 & 9.30 \\
\hline Ref Yield & 2.43 & 6.80 & 5.82 & 4.99 & 8.25 & 14.52 & 9.38 & 10.21 & 9.22 & 12.57 & 12.51 & 12.13 & 11.48 & 7.17 & 8.18 & 8.97 & 5.21 \\
\hline
\end{tabular}

Splitter Setting Guide
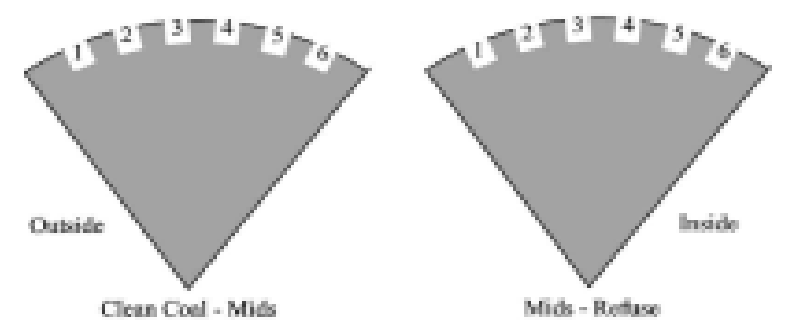
Table 3. Spiral Performance by Size Fraction for Selected Tests

\begin{tabular}{|l|l|l|l|}
\hline Test \# & $\mathbf{3}$ & $\mathbf{1 4}$ & $\mathbf{1 5}$ \\
\hline Date & $7 / 14$ & $9 / 13$ & $9 / 13$ \\
\hline CC/Mid & 2 & 3.5 & 3.5 \\
\hline Mid/Ref & 2 & 4 & 4 \\
\hline Feed gal/min & 59.1 & 36.6 & 36.2 \\
\hline Feed DTPH & 4.3 & 2.5 & 3.2 \\
\hline Feed \% Solids & 31.1 & 22.3 & 25.3 \\
\hline & & & \\
\hline 8 x 16 mesh SG50 & 1.87 & 1.91 & 1.92 \\
\hline 8 x 16 mesh Ep & 0.091 & 0.148 & 0.177 \\
\hline & & & \\
\hline 16 x 100 mesh SG50 & 1.74 & 1.58 & 1.58 \\
\hline $\mathbf{1 6} \times 100$ mesh Ep & 0.172 & 0.144 & 0.250 \\
\hline & & & \\
\hline 8x 100 mesh SG50 & 1.78 & 1.82 & 1.83 \\
\hline 8 x 100 mesh Ep & 0.160 & 0.135 & 0.200 \\
\hline
\end{tabular}

Several observations can be made about the results in Table 3 .

(1) All three tests produced a specific gravity of separation (SG50) of about 1.80 for the composite $8 \times 100$ mesh feed, with probable errors (Ep) between 0.135 and 0.200 , which is the normal range for coal spirals. This occurred even though test 3 was conducted at a significantly higher volumetric flow rate, solids concentration, and thus solids throughput than the other two tests.

(2) The range of Ep for the finer $16 \times 100$ mesh size fraction (0.144 to 0.250$)$ was higher than that of the coarser $8 \times 16$ mesh fraction (0.091 to 0.177), which is to be expected for gravity separation devices. However, this normal expectation did not hold true for the SG50 values, where the coarser size fraction had higher SG50s (1.87 to 1.92) than the finer size fraction (1.58 to 1.74). This is a unique characteristic of spirals when treating coarse material above 16 mesh, as demonstrated in some previous spiral test findings $(1-4)$.

(3) There does not appear to be a clear correlation between Ep and changes in operating conditions for these three tests. The only difference between tests 14 and 15 was in feed solids concentration, which resulted in a higher feed throughput in going from test 14 ( 2.5 tons $/ \mathrm{h}$ to test 15 (3.2 tons/h). In this comparison, test 14 produced a lower Ep for each size fraction, indicating that the lower throughput allowed for better spiral performance. However, test 3 had an even higher throughput ( 4.3 tons/h), but its performance was in between that of tests 14 and 15 .

\section{Conclusions}

The spiral performed well in cleaning the coarse $8 \times 16$ mesh size fraction, as demonstrated by the Ep ranging from 0.091 to 0.177 . This is in line with typical spiral performance. In addition, the presence of the coarser size fraction did not significantly affect spiral performance on the 
typical $16 \times 100$ mesh fraction, in which the Ep ranged from 0.144 to 0.250 . Changes in solids concentration and flow rate did not show a clear correlation with spiral performance.

However, for difficult-to-clean coals with high near-gravity material, such as this anthracite, a single-stage spiral cleaning such a wide size fraction may not be able to achieve the clean coal ash and yield specifications required. In the first place, while the performance of the spiral on the coarse $8 \times 16$ mesh fraction is good with regard to Ep, the cutpoints (SG50s) are high (1.87 to 1.92), which may result in a clean coal with a higher-than-desired ash content. And second, the combination of the spiral's higher overall cutpoint (1.80) with the high near-gravity anthracite results in significant misplaced material that increases the clean coal ash error. In a case such as this, one solution may be to reclean the clean coal and middlings from the first-stage spiral in a second stage spiral.

\section{References}

1. Gallagher, E., R. Ellis, G. Pitt, and A. Partridge, Operation of a 300 tph Spiral Concentrator Circuit at the German Creek Preparation Plant, $10^{\text {th }}$ International Coal Preparation Congress Proceedings, Edmonton, Canada, September 1986.

2. MacNamara, L., F. Addison, N. Miles, P. Bethell, and P. Davies, The Application of New Configurations of Coal Spirals, presented at Coal Prep '95, Lexington, Kentucky, May 1995.

3. MacNamara, L., N. Miles, P. Bethell, P. Davies, T. Toney, R. Moorhead, and B. Everitt, On Site Testing of the Compound Spiral, presented at Coal Prep '96, Lexington, Kentucky, May 1996.

4. Luttrell, G., J. Kohmuench, F. Stanley, and G. Trump, An Evaluation of Multi-Stage Spiral Circuits, presented at Coal Prep '99, Lexington, Kentucky, May 1999.

5. Zandhuis, P., and M. Ciocco, Spiral Testing of Anthracite Coal, Parsons Project Services Task Report to NETL, February 2001. 


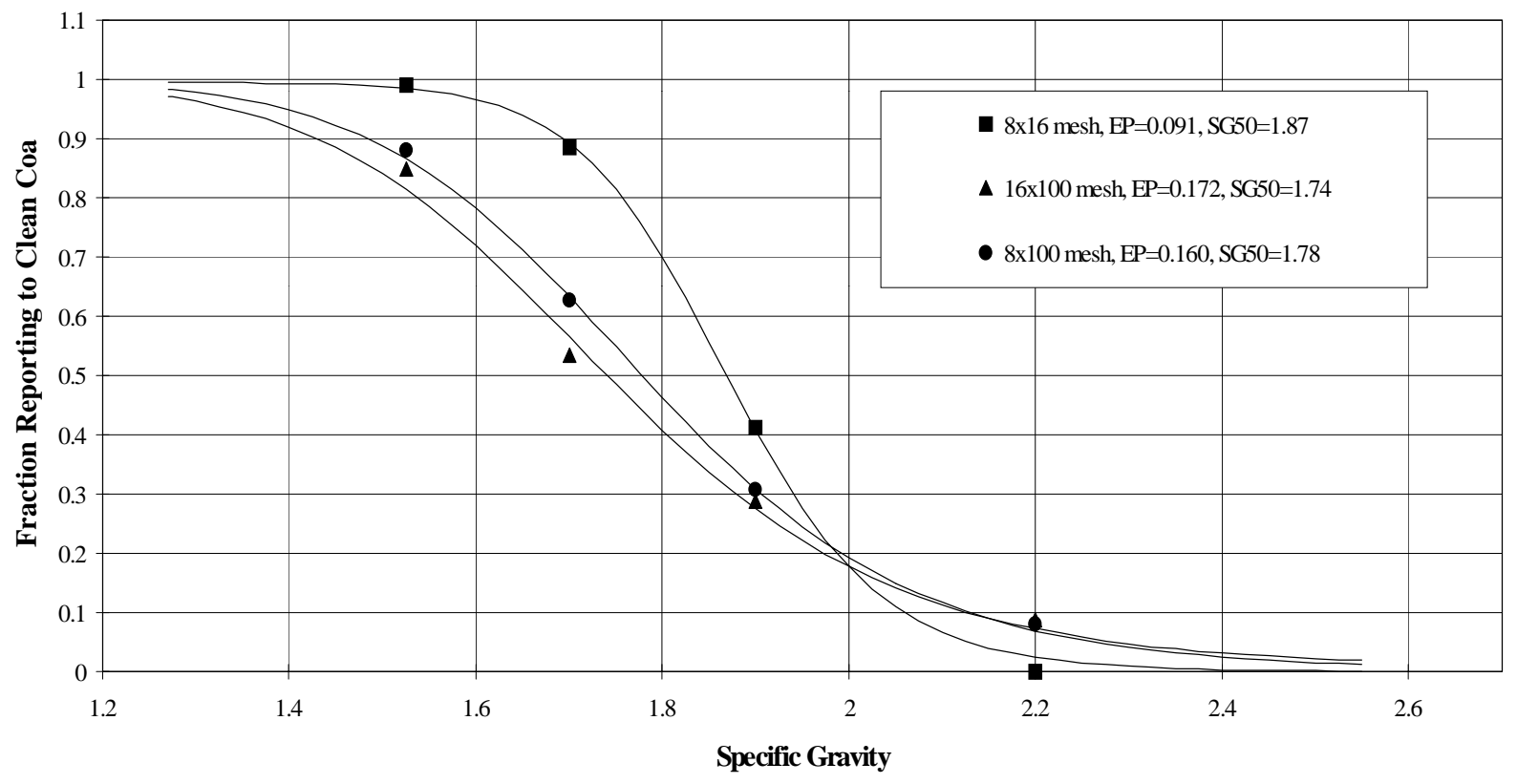

Figure 3. Spiral Test \#3 (CC vs. Mids + Ref)

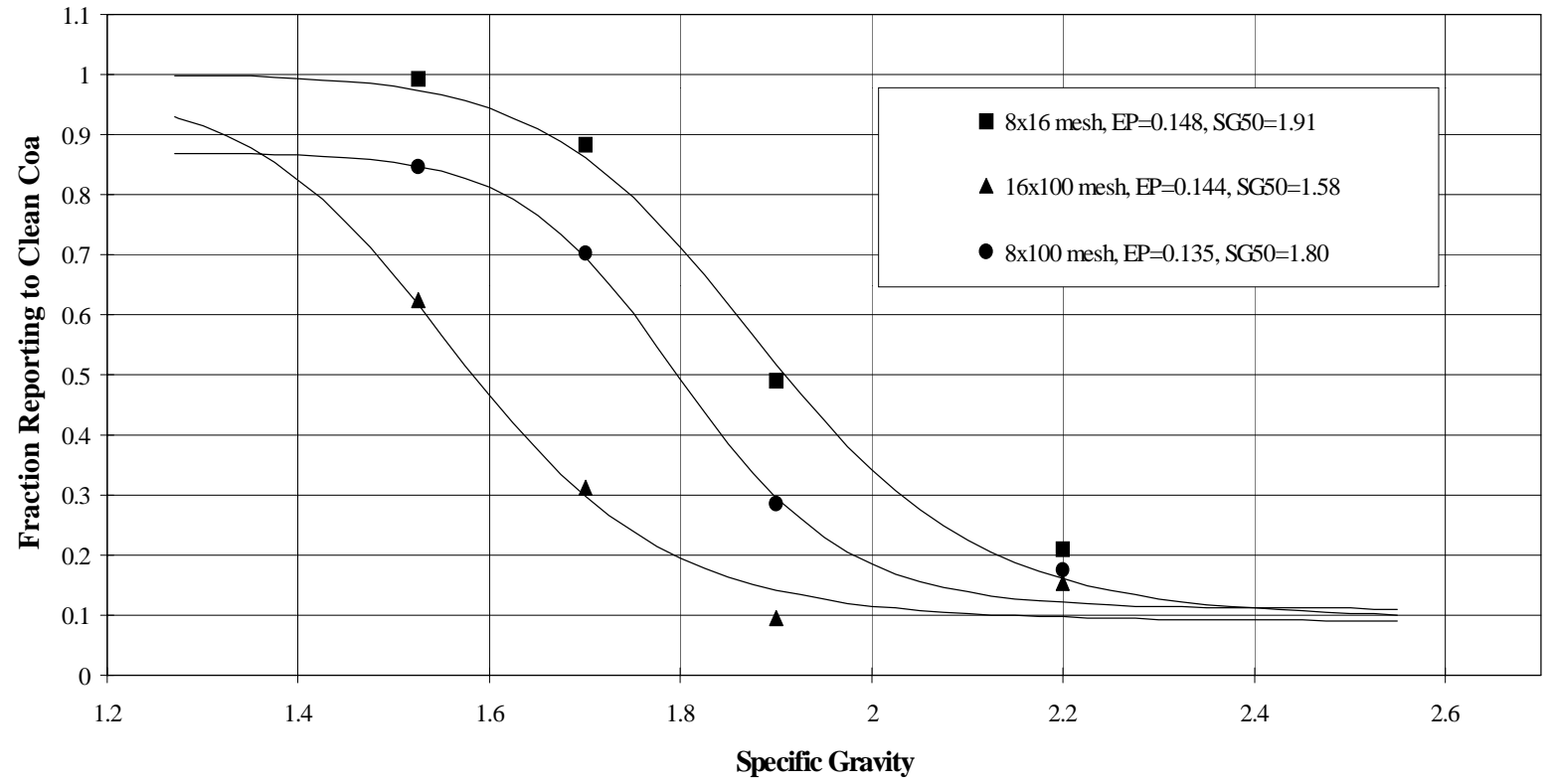

Figure 4. Spiral Test \#14 (CC vs. Mids + Ref) 


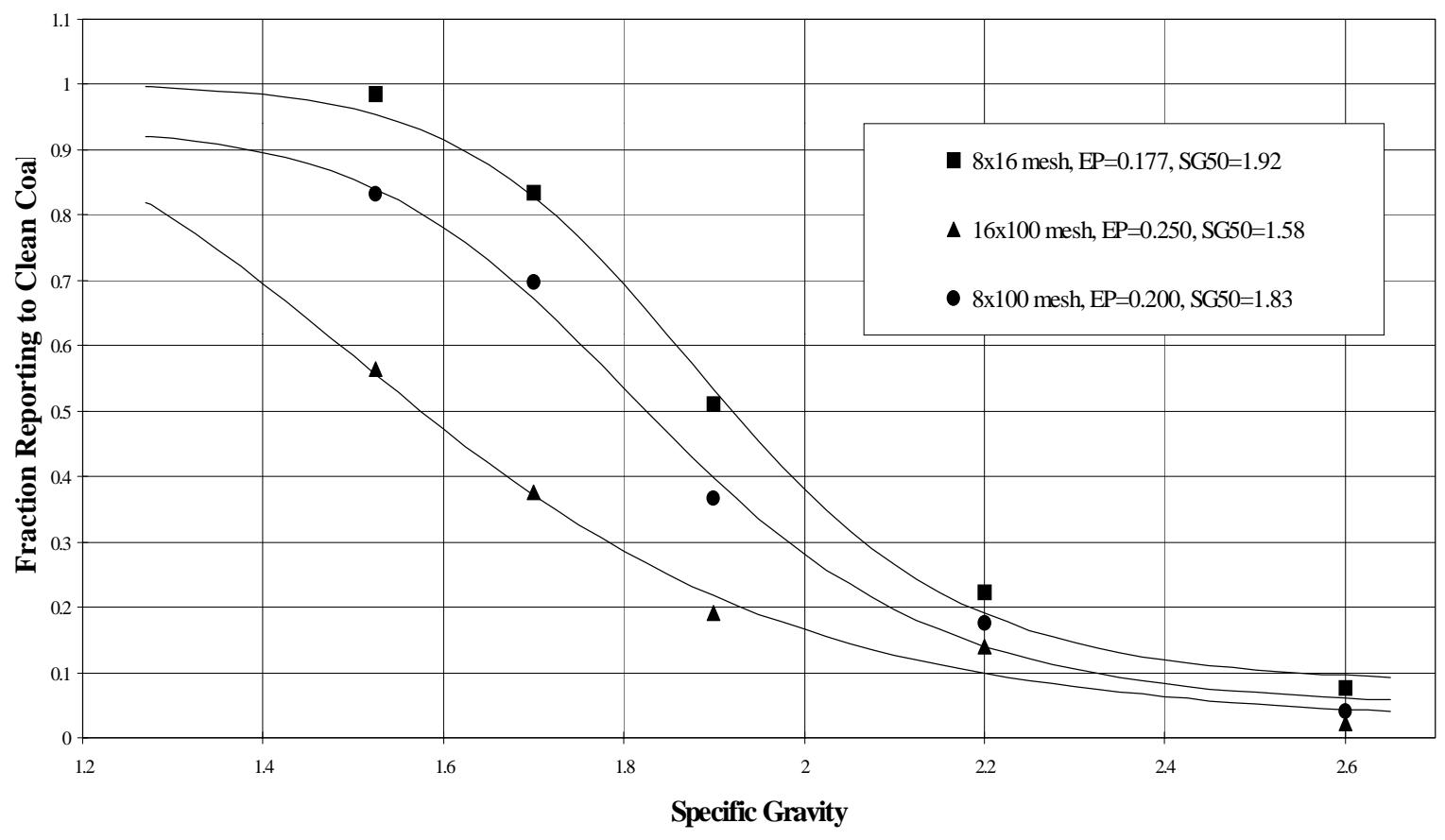

Figure 5. Spiral Test \#15 (CC vs. Mids + Ref) 